\title{
Use of the Distress Thermometer in Clinical Practice
}

\author{
KRISTIN K. OWNBY, PhD, RN, ACHPN, AOCN ${ }^{\circledR}, A N P-B C$
}

From UT Health Cizik School of Nursing, Houston, Texas

Author's disclosures of conflicts of interest are found at the end of this article.

Correspondence to: Kristin K. Ownby, PhD, RN, ACHPN, AOCN , ANP-BC, UT Health Cizik School of Nursing, 6901 Bertner Street, Houston, IX 77030. E-mail: kristin.k.ownby@uth.tmc.edu https://doi.org/10.6004/jadpro.2019.10.2.7 (c) 2019 Harborside $^{\mathrm{TM}}$

\begin{abstract}
Distress is experienced by many cancer patients, adversely affecting quality of life and cancer care. Although it is often manageable, it remains woefully underidentified and underreported. Distress can occur anytime during the cancer experience and is associated with depression, anxiety, missed appointments, and adverse outcomes. In 1999, the National Comprehensive Cancer Network (NCCN), recommended routine screening for distress in all cancer patients. The Distress Thermometer (DT) was developed as a simple tool to effectively screen for symptoms of distress. The instrument is a self-reported tool using a 0 -to-10 rating scale. Additionally, the patient is prompted to identify sources of distress using a Problem List. The DT has demonstrated adequate reliability and has been translated into numerous languages. The tool is easy to administer and empowers the clinician to facilitate appropriate psychosocial support and referrals.
\end{abstract}

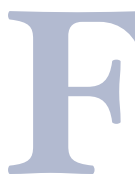

or many patients, the cancer care journey is fraught with distress, beginning with initial diagnosis, through the treatment decision-making process and cancer treatment, and into survivorship. Uncertainty about the future is commonly present throughout the cancer trajectory (Bultz \& Holland, 2006). The National Comprehensive Cancer Network Clinical Practice Guidelines in Oncology (NCCN Guidelines) for distress management define distress as "multifactorial unpleasant experience of a psychological (i.e., cognitive, behavioral, emotional), social, spiritual, and/or physical nature that may interfere with the ability to cope effectively with cancer, its physical symptoms, and its treatment" (NCCN, 2019). According to the NCCN Guidelines (2019), "Distress extends along a continuum, ranging from common normal feelings of vulnerability, sadness, and fears, to problems that can become disabling, such as depression, anxiety, panic, social isolation, and existential and spiritual crisis."

Whereas 7\% of the general population may experience distress at any given time, $25 \%$ to $60 \%$ of cancer patients report distress when they are assessed (Zabora, BrintzenhofeSzoc, Curbow, Hooker, \& Piantadosi, 2001). 
However, patient distress is an often overlooked but important constellation associated with physical and/or psychological symptoms. Up to $80 \%$ of patients with cancer attribute their distress to financial stressors (Khera, Holland, \& Griffin, 2017; Yabroff et al., 2016); 58\% have symptoms associated with depression, and $34 \%$ report symptoms of anxiety (Yabroff et al., 2016).

Research indicates patients who experience high levels of distress are less adherent to treatment plans, are more dissatisfied with overall care, experience poorer quality of life, and have poorer survival rates (Faller, Bülzebruck, Drings, \& Lang, 1999; Hamer, Chida, \& Molloy, 2009; Holland \& Alici, 2010; Von Essen, Larsson, Öberg, \& Sjödén, 2002). Untreated distress can result in higher health-care costs and prolonged rehabilitation (Abrahamson, 2010; Mitchell, Vahabzadeh, \& Magruder, 2011). Recognizing the impact of distress on the well-being of cancer patients, the NCCN Guidelines recommend routine screening for distress and identifying its sources.

All cancer patients are at risk for distress; however, research studies identified specific risk factors that increase the prevalence of distress among certain cancer groups. Studies have shown gender differences, with women experiencing higher levels of distress (Jacobsen et al., 2005; Shim, Shin, Jeon, \& Hahm, 2008). Younger patients experience higher levels of distress (Hegel et al., 2008). Married patients are less likely to experience distress than single patients, and patients diagnosed with specific cancers of the breast, head and neck, colon, lung, brain, or pancreas experience greater distress (Carlson et al., 2004; Hurria et al., 2009; Zabora et al., 2001). A decline in physical, emotional, and/or cognitive functioning has been associated with patient-reported distress as well (Keir, Calhoun-Eagan, Swartz, Saleh, \& Friedman, 2008). Stressors may include family relationship problems and feeling that the information provided about their cancer diagnosis and treatment was inadequate (Graves et al., 2007).

All patients with cancer must be viewed as being at risk for distress. Numerous cancer-related organizations, including the NCCN and the American College of Surgeons Commission on Cancer, advocate for screening for distress (American College of Surgeons, 2012; NCCN, 2019). Beginning in
2015, the Commission on Cancer requires institutions to screen for distress as part of their accreditation process. Institutions are required to develop a comprehensive plan that addresses six conditions: (1) inclusion of a psychosocial representative on the cancer committee; (2) determination of when distress screening occurs; (3) a method of screening; (4) selection of a well-validated screening tool; (5) protocols for further assessment and referrals; and (6) documentation of the process and program evaluation (Buxton et al., 2014). One commonly used screening tool is the NCCN Distress Thermometer (DT) and Problem List for patients (Figure 1).

\section{NCCN DISTRESS THERMOMETER AND PROBLEM LIST}

The NCCN introduced the DT as a screening tool to identify sources of distress. The NCCN recommends screening patients at the initial visit soon after diagnosis and at each visit, although the screening schedule may be revised as clinically indicated (NCCN, 2019). Important time points may include changes in disease activity such as remission, recurrence, or progression, or upon referral to palliative care (Carlson, Waller, \& Mitchell, 2012; Pirl et al., 2014).

The NCCN DT is a single-item tool using a 0 (no distress) to 10 (extreme distress)-point Likert scale resembling a thermometer. The patient rates his/her level of distress over the past week. The established cutoff score for further screening is a 4 (Donovan, Grassi, McGinty, \& Jacobsen, 2014; Jacobsen et al., 2005; NCCN, 2019). A recent study suggests a lower cutoff score of 3 when screening during the first month of a new cancer diagnosis (Cutillo at al., 2017). Studies have found that cutoff scores for specific patient populations vary from the established cutoff, including childhood cancer survivors (cutoff score of 3; van der Geest, van Dorp, Pluijm, \& van den Heuvel-Eibrink, 2018), cancer patients receiving palliative home-care services (cutoff score of 6; Ohnhäuser, Wüller, Foldenauer, \& Pastrana, 2018), and women recently diagnosed with breast cancer (cutoff score of 7; Ploos van Amstel et al., 2017).

The DT has been translated into 26 languages, including Spanish, and 18 of the translated versions have demonstrated adequate validity in validation studies (Donovan et al., 2014). One advan- 


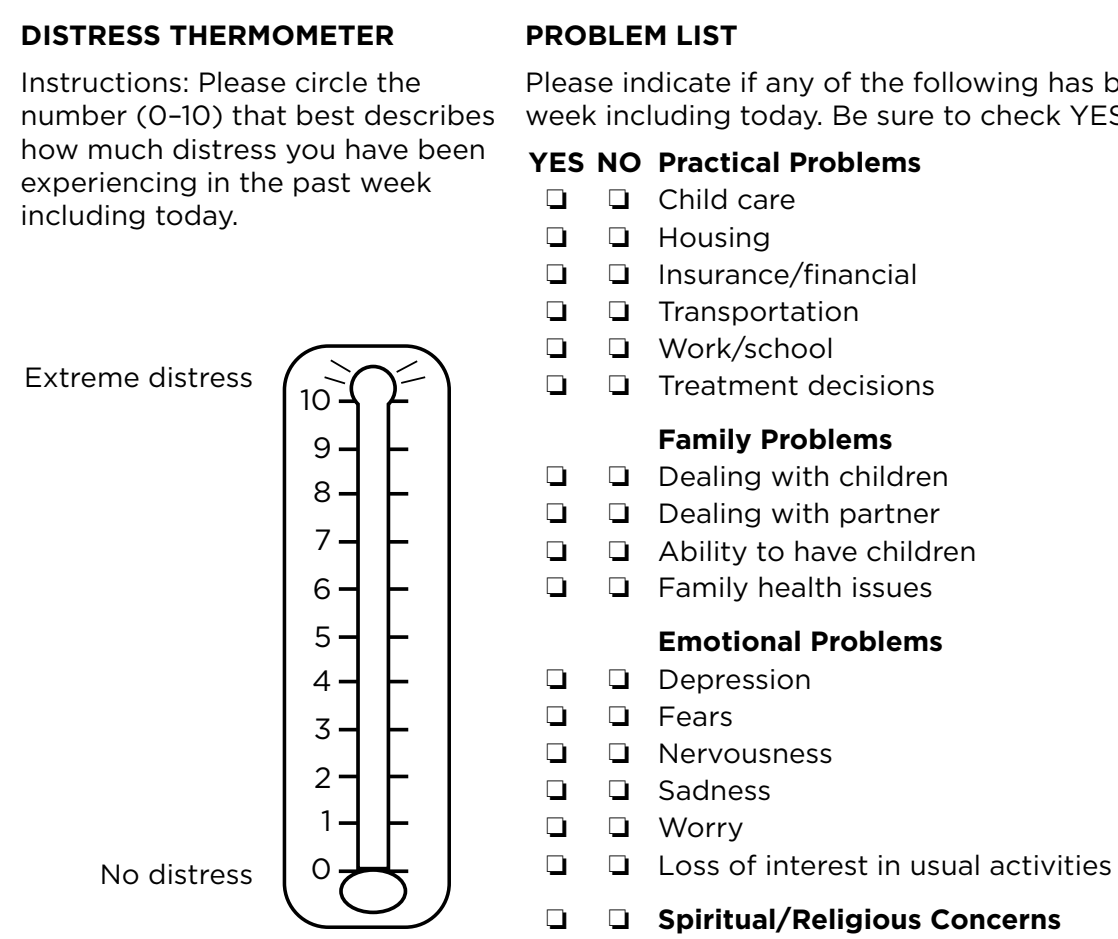

Instructions: Please circle the number (0-10) that best describes how much distress you have been experiencing in the past week including today.

Extreme distress

No distress

\section{PROBLEM LIST}

$\begin{array}{ccl}\text { YES NO } & \text { Practical Problems } \\ \square & \square & \text { Child care } \\ \square & \square & \text { Housing } \\ \square & \square & \text { Insurance/financial } \\ \square & \square & \text { Transportation } \\ \square & \square & \text { Work/school } \\ \square & \square & \text { Treatment decisions } \\ & & \text { Family Problems } \\ \square & \square & \text { Dealing with children } \\ \square & \square & \text { Dealing with partner } \\ \square & \square & \text { Ability to have children } \\ \square & \square & \text { Family health issues } \\ & & \text { Emotional Problems } \\ \square & \square & \text { Depression } \\ \square & \square & \text { Fears } \\ \square & \square & \text { Nervousness } \\ \square & \square & \text { Sadness } \\ \square & \square & \text { Worry } \\ \square & \square & \text { Loss of interest in usual activities } \\ \square & \square & \text { Spiritual/Religious Concerns }\end{array}$

Please indicate if any of the following has been a problem for you in the past week including today. Be sure to check YES or NO for each.

Other Problems:

Figure 1. NCCN screening tools for measuring distress. Adapted with permission from the $2019 \mathrm{NCCN}$ Clinical Practice Guidelines in Oncology (NCCN Guidelines ${ }^{\circledR}$ ) for Distress Management V.2.2019. (c) 2019 National Comprehensive Cancer Network, Inc. All rights reserved. The NCCN Guidelines ${ }^{\circledR}$ and illustrations herein may not be reproduced in any form for any purpose without the express written permission of NCCN. To view the most recent and complete version of the NCCN Guidelines, go online to NCCN. org. The NCCN Guidelines are a work in progress that may be refined as often as new significant data becomes available.

tage of the DT is its brevity: studies have shown that nurses need an average of only 2 minutes and 20 seconds to help a patient complete the tool (Musiello et al., 2017). Overall, it is easy to administer, and patients find the tool easy to use. Administration and interpretation of the DT are provided by a cancer provider.

The NCCN Problem List for patients is a 39item supplemental list of potential sources of distress (NCCN, 2019). The NCCN recommends incorporating the Problem List for patients as part of the assessment to assist the provider in identifying sources of patient distress. The NCCN Problem List provides a comprehensive list of categories, including practical, family, physical, and emotional problems, as well as spiritual/religious concerns. Not surprisingly, patients who score a 4 or higher on the DT select more items from the NCCN Problem List (VanHoose et al., 2015). Patients who report distress frequently select problems from the emotional domain, and worry is the item most frequently selected. Other items associated with risk for distress include problems from the physical domain, such as sleep and getting around, and problems from the emotional domain, such as nervousness (Clover et al., 2016). A common source of distress later on in the cancer care trajectory is financial strain (VanHoose et al., 2015).

Once screening has been completed and the results have been interpreted, the provider determines whether the patient needs to be referred for psychosocial support. Referrals can include psychologists, chaplains, and social workers. The cancer care provider may use community-based 
resources as well as resources provided by the institution based on the patient's preference.

\section{BARRIERS TO SCREENING}

Barriers to screening for distress do exist. For example, patients may have trouble understanding what the word "distress" means (Mitchell, 2013). Patient barriers to screening include language and cultural differences as well as literacy (Lo, Ianniello, Sharma, Sarnacki, \& Finn, 2016). Another barrier occurs when referring distressed patients for psychosocial services. Studies have also shown that patients who score high on the DT may not necessarily want help. Conversely, studies have shown that when patients were screened and did not receive any referrals or assistance, their levels of distress increased (Mitchell, 2013). Institutional barriers identified include insufficient time and training, lack of privacy for screening, poor documentation of results, discomfort discussing results, and a lack of resources for patient referrals (Chiang, Amport, Corjulo, Harvey, \& McCorkle, 2015; Girgis, Smith, \& Durcinoska, 2018).

\section{CONCLUSION}

Distress is considered the sixth vital sign in oncology care. Numerous research studies have demonstrated the prevalence of distress and the significant impact it has on the patient's quality of life and treatment success. Research continues to determine the validity of the DT and Problem List in various cancer populations based on ethnicity, cancer type, language, and age. Research is needed to validate interventions used to manage distress. Because the NCCN DT is a tool with wellestablished validity and brevity that is available in multiple languages and easy for the provider to interpret, the use of the instrument is being studied in other patient populations, including those with chronic obstructive pulmonary disease and acquired immune deficiency syndrome.

\section{Disclosure}

The author has no conflicts of interest to disclose.

\section{Disclaimer}

The National Comprehensive Cancer Network makes no warranties of any kind whatsoever regarding their content, use or application and dis- claims any responsibility for their application or use in any way.

\section{References}

Abrahamson, K. (2010). Dealing with cancer-related distress. American Journal of Nursing, 110(4), 67-69. https://doi. org/10.1097/01.NAJ.0000370162.07674.f6

American College of Surgeons. (2012). Cancer Program Standards 2012. Version 1.1: Ensuring patient-centered care. Chicago, IL: American College of Surgeons. Retrieved from https://www.facs.org/quality-programs/cancer/ coc/standards

Bultz, B. D., \& Holland, J. C. (2006). Emotional distress in patients with cancer: The sixth vital sign. Community Oncology, 3(5), 311-314. http://dx.doi.org/10.1016\%2 FS1548-5315(11)70702-1

Buxton, D., Lazenby, M., Daugherty, A., Kennedy, V., Wagner, L., Fann, J. R., \& Pirl, W. F. (2014). Distress screening for oncology patients: Practical steps for developing and implementing a comprehensive distress screening program. Retrieved from www.accc-cancer.org.

Carlson, L. E., Angen, M., Cullum, J., Goodey, E., Koopmans, J., Lamont, L.,...Bultz, B. D. (2004). High levels of untreated distress and fatigue in cancer patients. British Journal of Cancer, 90(12), 2297-2304. https://doi. org/10.1038/sj.bjc.6601887

Carlson, L. E., Waller, A., \& Mitchell, A. J. (2012). Screening for distress and unmet needs in patients with cancer: Review and recommendations. Journal of Clinical Oncology, 30(11), 1160-1177. https://doi.org/10.1200/ JCO.2011.39.5509

Chiang, A. C., Amport, S. B., Corjulo, D., Harvey, K. L., \& McCorkle, R. (2015). Incorporating patient-reported outcomes to improve emotional distress screening and assessment in an ambulatory oncology clinic. Journal of Oncology Practice, 11(3), 219-222. https://doi. org/10.1200/JOP.2015.003954

Clover, K., Oldmeadow, C., Nelson, L., Rogers, K., Mitchell, A. J., \& Carter, G. (2016). Which items on the distress thermometer problem list are the most distressing? Supportive Care in Cancer, 24(11), 4549-4557. https://doi. org/10.1007/s00520-016-3294-z

Cutillo, A., O’Hea, E., Person, S. D., Lessard, D., Harralson, T. L., \& Boudreaux, E. (2017). The distress thermometer: Cutoff points and clinical utility. Oncology Nursing Forum, 44(3), Al-A9. https://doi.org/10.1188/17.ONF.329336

Donovan, K. A., Grassi, L., McGinty, H. L., \& Jacobsen, P. B. (2014). Validation of the distress thermometer worldwide: State of the science. Psycho-Oncology, 23(3), 241250. https://doi.org/10.1002/pon.3430

Faller, H., Bülzebruck, H., Drings, P., \& Lang, H. (1999). Coping, distress, and survival among patients with lung cancer. Archives of General Psychiatry, 56(8), 756-762. Retrieved from https://www.ncbi.nlm.nih.gov/pubmed/10435611

Girgis, A., Smith, A. B., \& Durcinoska, I. (2018). Screening for distress in survivorship. Current Opinion in Supportive and Palliative Care, 12(1), 86-91. https://doi.org/10.1097/ SPC.0000000000000328

Graves, K. D., Arnold, S. M., Love, C. L., Kirsh, K. L., Moore, P. G., \& Passik, S. D. (2007). Distress screening in a multidisciplinary lung cancer clinic: Prevalence and predic- 
tors of clinically significant distress. Lung Cancer, 55(2), 215-224. https://doi.org/10.1016/j.lungcan.2006.10.001

Hamer, M., Chida, Y., \& Molloy, G. J. (2009). Psychological distress and cancer mortality. Journal of Psychosomatic Research, 66(3), 255-258. https://doi.org/10.106/j.jpsychores.2008.11.002

Hegel, M. T., Collins, E. D., Kearing, S., Gillock, K. L., Moore, C. P., \& Ahles, T. A. (2008). Sensitivity and specificity of the Distress Thermometer for depression in newly diagnosed breast cancer patients. Psychooncology, 17(6), 556-560. https://doi.org/10.1002/pon.1289

Holland, J. C., \& Alici, Y. (2010). Management of distress in cancer patients. Journal of Supportive Oncology, 8(1), 4-12.

Hurria, A., Li, D., Hansen, K., Patil, S., Gupta, R., Nelson, C.,... Kelly, E. (2009). Distress in older patients with cancer. Journal of Clinical Oncology, 27(26), 4346-4351. https:// doi.org/10.1200/JCO.2008.19.9463

Jacobsen, P. B., Donovan, K. A., Trask, P. C., Fleishman, S. B., Zabora, J., Baker, F., \& Holland, J. C. (2005). Screening for psychologic distress in ambulatory cancer patients. Cancer, 103(7), 1494-1502. https://doi.org/10.1002/ cncr. 20940

Keir, S. T., Calhoun-Eagan, R. D., Swartz, J. J., Saleh, O. A., \& Friedman, H. S. (2008). Screening for distress in patients with brain cancer using the NCCN's rapid screening measure. Psycho-Oncology, 17(6), 621-625. https://doi. org/10.1002/pon.1271

Khera, N., Holland, J. C., \& Griffin, J. M. (2017). Setting the stage for universal financial distress screening in routine cancer care. Cancer, 123(21), 4092-4096. https://doi. org/10.1002/cncr.30940

Lo, S. B., Ianniello, L., Sharma, M., Sarnacki, D., \& Finn, K. T. (2016). Experience implementing distress screening using the National Comprehensive Cancer Network distress thermometer at an urban safety-net hospital. Psycho-Oncology, 25(9), 1113-1115. https://doi.org/10.1002/ pon. 4214

Mitchell, A. (2013). Screening for cancer-related distress: When is implementation successful and when is it unsuccessful? Acta Oncologia, 52(2), 216-224. https://doi.or $\mathrm{g} / 10.3109 / 0284186$ X.2012.745949

Mitchell, A. J., Vahabzadeh, A., \& Magruder, K. (2011). Screening for distress and depression in cancer settings: 10 lessons from 40 years of primary-care research. Psycho-Oncology, 20(6), 160-174. https://doi.org/10.1002/pon.1943

Musiello, T., Dixon, G., O’Connor, M., Cook, D., Miller, L., Petterson, A.,...\& Johnson, C. (2017). A pilot study of routine screening for distress by a nurse and psychologist in an outpatient haematological oncology clinic. Applied Nursing Research, 33, 15-18. https://doi.org/10.1016/j. apnr.2016.09.005

National Comprehensive Cancer Network. (2019). NCCN Clinical Practice Guidelines in Oncology: Distress management. v2.2019. Referenced with permission from the NCCN Clinical Practice Guidelines in Oncology (NCCN Guidelines $^{\circledR}$ ) for Distress Management V.2.2019. (C) Na- tional Comprehensive Cancer Network, Inc. 2019. All rights reserved. To view the most recent and complete version of the guideline, go online to NCCN.org. Retrieved from http://www.nccn.org/professionals/physician_gls/distress.pdf.

Ohnhäuser, S., Wüller, J., Foldenauer, A. C., \& Pastrana, T. (2018). Changes in distress measured by the distress thermometer as reported by patients in home palliative care in Germany. Journal of Palliative Care, 33(1), 39-46. https://doi.org/10.1017/S1478951516000699

Pirl, W. F., Fann, J. R., Greer, J. A., Braun, I., Deshields, T., \& Fulcher, C.,...Bardwell, W. A. (2014). Recommendations for the implementation of distress screening programs in cancer centers: Report from the American Psychosocial Oncology Society (APOS), Association of Oncology Social Work (AOSW), and Oncology Nursing Society (ONS) joint task force. Cancer, 120(19), 2946-2954. https://doi. org/10.1002/cncr.28750

Ploos van Amstel, F., Tol, J., Sessink, K., van der Graaf, W. T., Prins, J., \& Ottevanger, P. (2017). A specific distress cutoff score shortly after breast cancer diagnosis. Cancer Nursing, 40(3), E35-E40. https://doi.org/10.1097/ NCC.0000000000000380

Shim, E.-J., Shin, Y.-W., Jeon, H. J., \& Hahm, B.-J. (2008). Distress and its correlates in Korean cancer patients: Pilot use of the distress thermometer and the problem list. Psycho-Oncology, 17(6), 548-555. https://doi. org/10.1002/pon.1275

van der Geest, I. M. M., van Dorp, W., Pluijm, S. M. F., \& van den Heuvel-Eibrink, M. M. (2018). The distress thermometer provides a simple screening tool for selecting distressed childhood cancer survivors. Acta Paediatrica, 107(5), 871-874. https://doi.org/10.1111/apa.14251

VanHoose, L., Black, L. L., Doty, K., Sabata, D., Twumasi-Ankrah, P., Taylor, S., \& Johnson, R. (2015). An analysis of the distress thermometer problem list and distress in patients with cancer. Supportive Care Cancer, 23(5), 12251232. https://doi.org/10.1007/s00520-014-2471-1

Von Essen, L., Larsson, G., Öberg, K., \& Sjödén, P. O. (2002). 'Satisfaction with care': Associations with health-related quality of life and psychosocial function among Swedish patients with endocrine gastrointestinal tumors. European Journal of Cancer Care, 11(2), 91-99. https://doi. org/10.1046/j.1365-2354.2002.00293.x

Yabroff, K. R., Dowling, E. C., Guy, G. P., Jr., Banegas, M. P., Davidoff, A., Han, X.,...Ekwueme, D. (2016). Financial hardship associated with cancer in the United States: Findings from a population-based sample of adult cancer survivors. Journal of Clinical Oncology, 34(3), 259-267. https://doi.org/10.1200/JCO.2015.62.0468

Zabora, J., Brintzenhofe Szoc, K., Curbow, B., Hooker, C., \& Piantadosi, S. (2001). The prevalence of psychological distress by cancer site.Psycho-Oncology, 10(1), 19-28. https:// doi.org/10.1002/1099-1611(200101/02)10:<19::AIDPON501>3.0.CO;2-6 